\title{
A systematic review of older people's perceptions of facilitators and barriers to participation in falls-prevention interventions
}

\author{
FRANGES BUNN*, ANGELA DICKINSON*, ELAINE \\ BARNETT-PAGE*, ELIZABETH MCINNES ${ }^{\dagger}$ \\ and KHIM HORTON**
}

\begin{abstract}
The prevention of falls is currently high on the health policy agenda in the United Kingdom, which has led to the establishment of many falls-prevention services. If these are to be effective, however, the acceptability of services to older people needs to be considered. This paper reports a systematic review of studies of older people's perceptions of these interventions. The papers for review were identified by searching electronic databases, checking reference lists, and contacting experts. Two authors independently screened the studies and extracted data on the factors relating to participation in, or adherence to, falls-prevention strategies. Twentyfour studies were identified, of which I2 were qualitative. Only one study specifically examined interventions that promote participation in falls-prevention programmes; the others explored older people's attitudes and views. The factors that facilitated participation included social support, low intensity exercise, greater education, involvement in decision-making, and a perception of the programmes as relevant and life-enhancing. Barriers to participation included fatalism, denial and under-estimation of the risk of falling, poor self-efficacy, no previous history of exercise, fear of falling, poor health and functional ability, low health expectations and the stigma associated with programmes that targeted older people.
\end{abstract}

$\boldsymbol{K E Y} \boldsymbol{W} \boldsymbol{W} \boldsymbol{D} \boldsymbol{S}$ - health attitudes, health-related behaviour, adherence, older people, falls prevention, systematic review.

\section{Background}

Falls are the leading cause of serious accidental injury (resulting in admission to hospital for four or more days) amongst people aged 65 or more years in the United Kingdom (Cryer 200I). Hip fractures are

* Centre for Research in Primary and Community Care, University of Hertfordshire, Hatfield, Hertfordshire, UK.

$\dagger$ Royal College of Nursing Institute, Oxford, UK.

** Division of Health and Social Care, University of Surrey, Guildford, Surrey, UK. 
an especially grave complication of falls in older adults, and result in more hospital admissions than any other type of injury (Jensen et al. I982), which during 2000 cost the National Health Service (NHS) in England around $f_{\mathrm{I}} .7$ billion (Easterbrook et al. 200I). There is a IO-20 per cent reduction in expected survival in the first year following a hip fracture (Cummings et al. 1985; Magaziner et al. 1989; Lu-Yao et al. 1994), and roughly one-half of survivors never recover normal function (Magaziner et al. 1989). Falling can also have serious psycho-social consequences, such as increased anxiety and depression, and can raise the fear of falling and reduce activity (Chandler et al. I996; Lachman et al. 1998; Yardley and Smith 2002). The prevention and management of falls in older people is a key target of the Department of Health (DOH 200I), and national guidelines on the topic have recently been produced by the UK National Institute for Health and Clinical Excellence (NICE 2004).

Older people are at particular risk of falls and fall-related injuries. Physiological changes with age, such as osteoporosis, postural instability, gait disturbances, diminished muscle strength, poor vision and cognitive impairment, as well as multiple medications, are all risk factors for falling. Environmental hazards, such as steps, stairs, beds, baths, showers, lighting, loose rugs, and the absence of grab rails and banisters, have also been identified as contributing to falls (Parker, Twemlow and Pryor 1996; Lilley, Arie and Chilvers 1995; Cryer 200I). Apart from the injury sustained in the fall, there are other potential consequences, such as loss of mobility, increased dependency and disability, hypothermia, pressure-related injuries and infections (DOH 200I).

In recent years, much attention in health-promotion research and in health care has focused on falls and falls prevention among older adults. In particular, several trials and systematic reviews have investigated the effectiveness of various falls-prevention strategies, and shown that effective interventions include multi-disciplinary, multifactorial risk-factor screening and intervention programmes, muscle strength and balance training, individually-tailored home exercise programmes, home modification, T'ai Chi programmes, medication review, and the follow up of patients who have fallen (Cryer 200I; Easterbrook et al. 2001; Gillespie et al. 2003; Parker, Gillespie and Gillespie 2005). Previous reviews have concentrated on quantitative evaluations of effectiveness, however, and have neglected the patients' views about the acceptability of the programmes. As a result, service or guideline developers have little information by which to improve acceptability or adherence. 


\section{Aims and objectives}

The aim was to undertake a systematic review of the research evidence on the barriers and facilitators which influence older people's participation in, and adherence to, falls-prevention programmes and interventions, and to identify the measures that promote acceptance. The exercise was expected to identify examples of good practice. Five review questions were to be asked of each published report:

I. What influences whether older people participate in falls-prevention programmes?

2. What factors prevent older people from taking part in falls-prevention programmes?

3. What do older people perceive to be the benefits of falls-prevention programmes?

4. What interventions are effective in promoting participation in fallsprevention programmes?

5. What are the key components of successful interventions for promoting participation in falls-prevention programmes?

\section{The search strategy and coding}

The studies of interest were those that evaluated interventions to promote adherence to, or participation in, a falls-prevention programme or strategy, and that identified the factors that influenced whether older people participated and were compliant. Further details of the inclusion criteria are provided in Table I. We searched for all potentially relevant literature, both published and unpublished, with no date restrictions, and included relevant evidence regardless of country of origin. In order to find all potential studies we used a broad, topicoriented approach. Methodological search filters were not used, as many non-randomised studies are not key-worded by study design (Peersman et al. I998). The search terms were both free-text and 'medical subject heading' (MeSH) terms and they were combined with the appropriate Boolean operators. Details of the search terms and the databases that were searched are given in Table 2. In addition, lists of references in the selected papers were checked for otherwise unfound contributions. To identify unpublished or grey literature, we contacted field researchers and experts, including the guideline development group of NICE. The searches were conducted in January 2005 . 
T A B L E I. Inclusion criteria for the systematic review

\begin{tabular}{|c|c|c|}
\hline Attribute & Intervention studies & Other studies of facilitators and barriers \\
\hline Type of study & $\begin{array}{l}\text { Randomised-control trials, controlled } \\
\text { trials, controlled before/after studies }\end{array}$ & $\begin{array}{l}\text { Any type, including non-intervention } \\
\text { and qualitative. } \\
\text { Excluding editorials/policy documents/ } \\
\text { single case studies. }\end{array}$ \\
\hline Participants & Older people (mainly aged $65+$ years) & Older people (mainly aged $65+$ years) \\
\hline Intervention & $\begin{array}{l}\text { Main focus: intervention to promote } \\
\text { participation in falls-prevention pro- } \\
\text { grammes }\end{array}$ & $\begin{array}{l}\text { Examining barriers and facilitators } \\
\text { to participation in programmes/inter- } \\
\text { ventions. }\end{array}$ \\
\hline Setting & $\begin{array}{l}\text { All settings (including A\&E/care home/ } \\
\text { hospital) }\end{array}$ & $\begin{array}{l}\text { All settings (including A\&E/care home/ } \\
\text { hospital) }\end{array}$ \\
\hline Outcomes & $\begin{array}{l}\text { Rates of compliance/adherence with } \\
\text { programme/strategy } \\
\text { Predictors of compliance/adherence } \\
\text { Participants' views and experiences of } \\
\text { programme/strategy }\end{array}$ & $\begin{array}{l}\text { Measures of/self reports of barriers/ } \\
\text { benefits of participation. } \\
\text { Participant views/experiences of falls } \\
\text { prevention-strategies. }\end{array}$ \\
\hline
\end{tabular}

Note: A\&E Accident and emergency hospital departments (= casualty wards).

\section{T A B L E 2. The search strategy}

\section{Search terms and sequence}

\#I. (fall or falls or falling or faller* or fallen or slip or trips or tripped).

$\#_{3}$. femoral neck fractures. $\quad \#_{4}$. $\left(\#_{1}\right.$ or $\#_{2}$ or $\left.\#_{3}\right)$.

\#5. (old or older or senior* or elder* or aged or geriatric* or middleage*) \#6. (\#4 and $\#_{5}$ )

\#7. (impact* or psycholog* or psychosocial or emotion or experience* or subjective* or status

or perception* or consequence* or sequelae or effect* or meaning* or rating* or view*)

\#8. (\#6 and \#7)

\section{Abstract databases searched}

AMED (Allied and Complementary Medicine Database) I985-2005

CINAHL (Cumulative Index to Nursing and Allied Health Literature) I982-2005

GCTR (Cochrane Controlled Trials Register) Cochrane Library Issue I, 2005

DARE (Database of Reviews of Effectiveness ); Cochrane Library Issue I, 2005

HTA (Health Technology Assessment Database ) I988-2005

HMIC (Health Management and Information Consortium ) I983-2005. Includes the database of

The King's Fund (London), the Department of Health Library and Information Service, and

The Nuffield Institute for Health (Leeds).

MEDLINE ig66-2005

UK National Research Register (Issue I 2005).

NHS Economic Evaluations Database I968-2005

PsychInfo I872-2005

SIGLE (System for Information on Grey Literature) $1976-2005$

ZETOC (British Library Electronic Table of Contents) I993-2005

All citations identified by the above searches were downloaded into an Endnote database. Two authors independently screened the titles and abstracts against the inclusion criteria and extracted data from the full papers 
T А в L E 3. Core principles of quality assessment for main study designs

\begin{tabular}{|c|c|}
\hline Study type & Scoring strategy and criteria \\
\hline $\begin{array}{l}\text { Randomised-controlled } \\
\text { trials }\end{array}$ & $\begin{array}{l}\text { Quality scoring: } \\
\text { Allocation to treatment groups concealed } \\
\text { Study blinded, if possible } \\
\text { All randomised participants included in the analysis (intention to treat) } \\
\text { Withdrawals/drop-outs, reasons given for each group }\end{array}$ \\
\hline $\begin{array}{l}\text { Cross-sectional } \\
\text { studies/surveys }\end{array}$ & $\begin{array}{l}\text { Quality scoring: } \\
\text { Selected subjects are representative (all eligible or a random sample) } \\
\text { 8o per cent or more agreed to participate } \\
\text { Exposure/outcome status ascertained in a standardised way }\end{array}$ \\
\hline Qualitative studies & $\begin{array}{l}\text { Assessed on seven criteria, scored as 'yes', 'no', 'partly' or 'unclear': } \\
\text { Scope and purpose, e.g. clearly stated question, clear outline of } \\
\text { theoretical framework } \\
\text { Design, e.g. discussion of why particular approach/methods chosen } \\
\text { Sample, e.g. adequate description of sample used and how sample } \\
\text { identified and recruited } \\
\text { Data collection, e.g. systematic documentation of tools/guides/ } \\
\text { researcher role, recording methods explicit } \\
\text { Analysis, e.g. documentation of analytic tools/methods used, evidence } \\
\text { of rigorous/systematic analysis } \\
\text { Reliability and validity, e.g. presentation of original data, how } \\
\text { categories/concepts/themes developed and were they checked by } \\
\text { more than one author, interpretation, how theories developed, } \\
\text { triangulation with other sources } \\
\text { Generalisability, e.g. sufficient evidence for generalisability or limits } \\
\text { made clear by author(s) }\end{array}$ \\
\hline
\end{tabular}

onto a specially designed form. Disagreements were resolved by discussion. Two reviewers independently assessed the quality of the selected studies using design assessment checklists. The quality criteria were informed by several sources (Higgins 2006; Thomas et al. 2003; Spencer et al. 2003) and are similar to established tools (Mays and Pope ı995; Giacomini and Cook 2000). The core quality-assessment principles are summarised in Table 3 .

The papers were categorised by study design using the following categories: randomised-controlled trial, controlled trial, before/after study (with or without control), cohort study (with or without concurrent controls), case control, survey, process evaluation and qualitative study. Process evaluations were categorised in terms of the intervention's implementation, its acceptability, and the explanations given about why an intervention was successful or unsuccessful. Non-intervention studies (cohort, case-control and cross-sectional survey designs) were differentiated by whether they aimed to identify or analyse the factors that influence adherence with falls and fracture prevention, and whether they 
sought older people's views about such programmes. Data were also extracted on the type, location and duration of the intervention, the characteristics of the participants and providers, the country, the main aims of the study, and the outcome measures.

\section{The reviewed studies}

The electronic searches yielded 6,I9I records from all data bases, including duplicates. Of those, I34 appeared potentially relevant and a hard copy was obtained for screening. After full text review, 24 studies met the inclusion criteria. One study (Yardley and Todd 2005) was in two parts using both quantitative and qualitative methods. The remaining studies were excluded because they did not meet the inclusion criteria or because the quality was poor. Details of the studies' aims, settings and methods, of the interventions (where appropriate), and of the participants are summarised in Table 4 (further details are available on request from the authors).

Seven studies took place in the UK (Table 4, rows I, 2, 5, 7, 8/9, I9, 20); seven in the USA (6, I0, II, I4, I6-I8); five in Australia (3, 4, I2, 23, 24); and five in Canada (I3, I5, 21, 22, 25). Thirteen studies focused on people living in the community (I, 3-5, 8/9, IO-I5, I9, 20); one on a combination of community dwellers and nursing/residential home residents (6); and three on people living in a continuing-care retirement village (I6-18). Two studies were conducted in hospital $(2,7)$. Of the studies in English-speaking countries, only a few examined the health-promotion needs of non-English speaking groups $(5,21,25)$. In the majority of the studies, the participants were aged 60 or more years, but in one (13) they were aged 55 or more years. The participants were variously those at high risk of falling or the 'healthy and active'. Sample sizes ranged from eight to 89 in the qualitative studies, and from 19 to $\mathrm{I}, 5 \mathrm{OO}$ in the quantitative studies.

Only one study (I8) evaluated an intervention (more exercise) explicitly to promote adherence to, or participation in, a falls-prevention programme or strategy. Two studies were process evaluations. One (I) looked at the implementation of and adherence to a nurse-led falls-prevention programme, and the other (I3) examined the acceptability to older people of line-dancing and T'ai Chi classes. The other studies all identified factors involved in older people participating or complying with falls-prevention programmes. Five of these examined older people's general views on falls and falls prevention $(2,4,5,6,8)$, two examined specific adherence factors, such as self-efficacy $(3$, I2), and the rest aimed to identify the factors that 
influence adherence to falls and fractures prevention interventions. The following sections of the paper present the findings about three groups of studies concerned respectively with falls and falls prevention in general $(\mathrm{N}=8)$, exercise interventions (II), and home modifications or assistive devices, e.g. canes (5).

\section{The methodologies and quality of the studies}

The qualitative studies employed methodologies that ranged from phenomenology to discourse analysis, although some did not make the method clear (Tables 5 and 6). In general, the studies had clearly defined aims, and gave adequate descriptions of the sampling and data collection, but there was limited evidence of sample validation, triangulation or assessments of generalisability. All examined people's views or knowledge of falls prevention or strategies to reduce falls, in most cases using semistructured interviews and focus groups, and with the findings reported as themes and categories. Five examined perceptions, motivations and barriers to physical activity (Gavin and Myers 2003; Grossman and Stewart 2003; Resnick and Spellbring 2000; Sharon et al. I997; Stead et al. I997), and two these same reactions to home modification or assistive devices (Aminzadeh and Edwards i998; Clemson, Cusick and Fozzard I999), and the remainder examined more general reactions.

The quantitative studies used various methods to measure or review predictors of increased exercise adherence, behaviour change, falls history, fear of falling, ability and confidence, self-efficacy, participation rates, and activity levels. Overall the quality was low to fair. Some had small sample sizes (e.g. Hinman 1998; Resnick 2002) and some reached conclusions and recommendations that were questionably supported by the data. For example, although Cheal and Clemson (200I) was treated as a qualitative study, it also had a quantitative component, but the uncontrolled 'before and after' design and very small sample were inadequate to assess the efficacy of the intervention. In both the randomised-controlled trials, the allocation to the samples was not fully described and neither reported a sample size calculation or an intention-to-treat analysis. Only Resnick (2002) gave details of numbers lost to follow-up.

Of the surveys, two stated that they used a random sample (Bruce, Devine and Prince 2002; Edwards et al. 2003), and three a convenience sample (Aminzadeh and Edwards 2000; Hinman 1998; Yardley and Smith 2002). Only three studies gave the response rates (Bruce, Devine and Prince 2002; Edwards et al. 2003; Yardley and Smith 2002), none of 


\begin{tabular}{|c|c|c|c|c|c|}
\hline Study & Authors & Aim & Method/intervention & Participants & Setting \\
\hline \multicolumn{6}{|c|}{ A. Falls prevention: general } \\
\hline I & Allen (I999) & $\begin{array}{l}\text { Explored recruitment to and } \\
\text { attendance at } \\
\text { falls-prevention programme. }\end{array}$ & $\begin{array}{l}\text { Part of RCT of a nurse-led falls- } \\
\text { prevention programme (included } \\
\text { medication review and exercise). }\end{array}$ & $\begin{array}{l}\text { Recently fallen aged } \\
65+, \mathrm{N}=2 \mathrm{O} 2\end{array}$ & Community, UK \\
\hline 2 & Ballinger (2000) & $\begin{array}{l}\text { Explored perspectives on falls and } \\
\text { falling among those with hip } \\
\text { fracture. }\end{array}$ & $\begin{array}{l}\text { Qualitative study with: semi- } \\
\text { structured interviews/discourse } \\
\text { analysis. }\end{array}$ & $\begin{array}{l}\text { Age: } 65+(M=8 \mathrm{I}) \\
\mathrm{N}=8(7 \mathrm{f}, \mathrm{I} \mathrm{m})\end{array}$ & Hospital, UK \\
\hline 3 & Cheal (200I) & $\begin{array}{l}\text { Evaluation of Steady As } Y_{o u} \text { Go } \\
\text { programme (enhance self-efficacy) }\end{array}$ & $\begin{array}{l}\text { Before/after study. Qualitative } \\
\text { semi-structured interviews. }\end{array}$ & Age: $65+, N=8$ & Community, Australia \\
\hline 4 & $\begin{array}{l}\text { Commonwealth } \\
\text { DHAC } \\
(2000)\end{array}$ & $\begin{array}{l}\text { Explored information needs/ } \\
\text { perceptions of falls and their } \\
\text { prevention. }\end{array}$ & $\begin{array}{l}\text { Qualitative study. } 7 \text { discussion } \\
\text { groups, Io in-depth interviews. } \\
\text { Thematic analysis. }\end{array}$ & $\begin{array}{l}\text { Age: } 65+, \text { and carers. } \\
\mathrm{N}=59\end{array}$ & $\begin{array}{l}\text { Rural/metro } \\
\text { community dwellers, } \\
\text { Australia }\end{array}$ \\
\hline 5 & $\begin{array}{l}\text { Health Education } \\
\text { Board for Scotland } \\
(2003)\end{array}$ & $\begin{array}{l}\text { Explored constructions of the risks of } \\
\text { falling. }\end{array}$ & $\begin{array}{l}\text { Qualitative study, } 2 \text { phases. Second } \\
\text { phase used to validate and explore } \\
\text { data from first phase. Individual and } \\
\text { group interviews. }\end{array}$ & $\begin{array}{l}\text { Age: } 60+. \text { Phase I } \\
\mathrm{N}=39(\mathrm{I} 4 \mathrm{~m}, 25 \mathrm{f}) \\
\text { Phase } 2 \mathrm{~N}=50(40 \mathrm{f} \\
\text { Io } \mathrm{m})\end{array}$ & $\begin{array}{l}\text { Community (rural and } \\
\text { urban), UK }\end{array}$ \\
\hline 6 & Hinman (1998) & $\begin{array}{l}\text { Described beliefs held by older adults } \\
\text { regarding stability, cause and } \\
\text { control of their falls. }\end{array}$ & $\begin{array}{l}\text { Survey. } 8 \text { brief closed questions (no } \\
\text { mention of validation). Convenience } \\
\text { sample, no information on response } \\
\text { rate. }\end{array}$ & $\begin{array}{c}\text { Age: } 64-9 \mathrm{I}(\mathrm{M}=79) \\
\mathrm{N}=25(\mathrm{I} 5 \mathrm{f}, \text { Io } \mathrm{m})\end{array}$ & $\begin{array}{l}\text { Community and } \\
\text { residential care, USA }\end{array}$ \\
\hline 7 & Simpson (2003) & $\begin{array}{l}\text { Examined the precautions older } \\
\text { people are prepared to take to } \\
\text { prevent falls. }\end{array}$ & $\begin{array}{l}\text { Qualitative, semi-structured inter- } \\
\text { views. Recorded by hand-taken } \\
\text { notes. }\end{array}$ & $\begin{array}{l}\text { Age: } 65+(M=83) \\
N=32(26 \mathrm{f}, 6 \mathrm{~m})\end{array}$ & Hospital, UK \\
\hline 8 & Yardley (2005) Part I & $\begin{array}{l}\text { Identified negative aspects of falls } \\
\text { prevention communications and } \\
\text { improving messages. }\end{array}$ & $\begin{array}{l}\text { Qualitative study including focus } \\
\text { groups and 2I individual interviews. }\end{array}$ & $\begin{array}{l}\text { Age: } 6 \mathrm{I}-94 \cdot \mathrm{N}=66 \\
(4 \mathrm{I} \mathrm{f}, 24 \mathrm{~m})\end{array}$ & Community, UK \\
\hline
\end{tabular}


Yardley (2005) Part 2 To determine which beliefs and feelings have greatest impact on

intentions to undertake fallsprevention activities. Influence of different messages.

\section{B. Falls prevention: exercise}

Io Boyette (I997) and concerns about a strength-
Assess initiation to and adherence with a strength-training programme.

To understand older adults' attitudes training intervention and to identify factors that determined their adherence.

Examined whether fear of falling reduced recreational physical activity levels in healthy older women.

Explored participation and adherence to T'ai Chi and line-dancing classes.

Explored perceptions, motivation and barriers to physical activity
Questionnaires/ structured

interviews on attitudes to balance

training (BT), beliefs/feelings about

falling. Randomised to one of four groups: (a) leaflet on positive benefit of BT, (b) leaflet describing need to do BT, (c) both leaflets; (d) no leaflet.

Follow-up subset for 6-months of a previous 4-month strength-training and flexibility intervention.

Initiation defined: completing programme/attending $75 \%$ of sessions. Adherence defined: continuing exercises 6 months after intervention.

Qualitative study, 3 focus groups (I Io f, I $7 \mathrm{~m}$, I of $7 \mathrm{~m} / \mathrm{f}$ ). Participants drawn from Boyette (I997).

Excluded if depressed, cognitive impairment or cardiovascular disease.

Cross-sectional analysis of data from RCT of calcium supplements to prevent fractures. Measured fear of falling and physical activity (validated scales). $27 \%$ response rate.

Process evaluation with qualitative and survey elements. People enrolling for T'ai Chi/line-dancing classes. $75 \%$ reported good health.

In-depth interviews using open-ended questions. Details of data analysis not given.

$$
\begin{aligned}
& \text { Age: } 60-95 \\
& (\mathrm{M}=74 \cdot 7), \mathrm{N}=7 \mathrm{I} 5, \\
& 73 \% \mathrm{f}
\end{aligned}
$$

Age: $\mathrm{M}=7 \mathrm{I} \cdot 3 \cdot \mathrm{N}=46$ (33 f, I3 m). Healthy older adults.

Aged: $6 \mathrm{I}-82, \mathrm{~N}=23$

Age: $70-85(\mathrm{M}=75.2)$. Community, Australia Ambulatory $\mathrm{f}$

$\mathrm{N}=\mathrm{I} 5 \mathrm{OO}$

Age: $55+, \mathrm{N}=328$.

Mostly f $(85 \%)$, white $(97 \%)$

Age: $75+(\mathbf{M}=80)$, $\mathrm{N}=33$. Sedentary/

Community, USA
Community, USA

Community, UK

Community, USA

(1) 


\begin{tabular}{lcc}
\hline Study & Authors & Aim \\
\hline I5 & Rejeski (I997) & $\begin{array}{c}\text { Examined predictors of exercise } \\
\text { compliance. }\end{array}$ \\
I6 & Resnick (2000) & $\begin{array}{l}\text { Explored factors influencing adher- } \\
\text { ence to an exercise programme. }\end{array}$
\end{tabular}

I7 Resnick (200I)
Tested model of exercise behaviour, explored factors influencing adherence to an exercise programme.

Assessed effect of intervention on self-efficacy, exercise activity, falls and fall-related injuries.

Investigated factors influencing participation in physical activity.

Identified commonly-feared consequences of falling and whether these lead to activity avoidance.
Survey (random sub-sample of large RCT of Vit D). $75 \%$ response rate. Measured fear of falling at baseline and at six months (validated scales).
RCT. Compared health education, aerobic exercise and resistance exercise on self-reported disability. Knee osteoarthritis and selfreported difficulties with ADLs.

Qualitative study. Open-ended interviews with members of a walking group.

Survey. Assessed self-efficacy/ motivation, fear of falling and health status using validated scores. Association between above factors and exercise adherence (session attendance).

RCT, WALC intervention (walk, address pain, fear and fatigue, learn about exercise and verbal encouragement). Control: routine care assessment and treatment when necessary. Outcomes: exercise self-efficacy, health status, exercise behaviour and activity.

Qualitative study. Focus groups.

Age $: 65-75+. \mathrm{N}=6$ groups of $6-8(3$ groups aged $65^{-74}, 3$ aged $75+)$

Age: $75+(\mathbf{M}=8 \mathrm{I})$.

$\mathrm{N}=224(\mathrm{I} 06 \mathrm{~m}$,

II 8 f), Healthy

people
Continuing care retirement village, USA

Continuing care

retirement village, USA

\section{Community care} retirement

community, USA

\section{Community, UK}

\section{Community, UK}




\section{G. Falls prevention: home modification/assistive devices}

2I Aminzadeh (2000) Explored factors associated with cane use.

22

Aminzadeh (1998)

Views on the use of assistive devices.
23

Clemson (I999)

Cumming (200I)

$25 \quad$ Edwards (2003)

\section{Examined compliance with} home-hazard advice.

Examined adherence/predictors of adherence, to home modification recommendations by an OT.
Identified predictors of bathroom safety-device use (e.g. grab-bar/ rails).
Questionnaires. Convenience sample. Used cognitive mediator instrument - designed for this study (not clear if validated).

Qualitative study. 4 focus groups. Taped and transcribed categories established.

Qualitative study. Semi-structured in-depth ethnographic interviews

Compliance study (part of RCT of OT falls-prevention intervention).

I2 month follow-up.

Descriptive comparative study, face-to-face interviews. Measured grab-bar use and falls history

(validated scales) and used logistic regression to identify predictors of grab-bar use. $62.5 \%$ response rate.
Age: $65+(M=77)$.

$\mathrm{N}=$ I06. $48 \%$ used

canes

Age: $\mathrm{M}=72.2 . \mathrm{N}=30 \quad$ Community, Canada Italian and British

Canadian) $70 \%$ f

Age: $65+, \mathrm{N}=9$ received home

safety advice)

Age: $65+(M=76.4)$.

$\mathrm{N}=\mathrm{I} 78,56 \%$

Age: $60+(\mathbf{M}=73.9)$, $76 \%$ f. $\mathrm{N}=55^{\circ}$

(French/English-

speaking, no cogni-

tive impairment

$32 \%$ fell previous

year
Community, Canada

Community, Australia

Community (recruited at hospital),

Australia.

Community, Canada

Notes: DHAC: Department of Health and Aged Care, Commonwealth of Australia. f: female. m: male. M=average or arithmetic mean. RCT: randomised controlled trial. Vit: Vitamin. WALC: Women against lung cancer. Full citations of the included studies are in the List of References. 
T A в L E 5. Methodological approaches used in included studies

\begin{tabular}{|c|c|}
\hline Methodology & Studies \\
\hline Qualitative $(\mathrm{n}=\mathrm{I} 2)$ & $\begin{array}{l}\text { Aminzadeh i998, Ballinger 2000, Cheal 2001, Clemson I999, } \\
\text { Commonwealth of Australia 2000, Grossman 2003, Health Education } \\
\text { Board for Scotland 2003, Resnick 2000, Sharon I997, Simpson 2003, } \\
\text { Stead I997, Yardley and Todd } 2005 \text { (n.b. Cheal 2001, Resnick 2000, } \\
\text { Yardley } 2005 \text { had quantitative components). }\end{array}$ \\
\hline $\begin{array}{l}\text { Randomised controlled } \\
\text { trials }(\mathrm{n}=2)\end{array}$ & Rejeski i997, Resnick 2002. \\
\hline $\begin{array}{l}\text { Cross sectional/survey } \\
(\mathrm{n}=6)\end{array}$ & $\begin{array}{l}\text { Aminzadeh 2000, Bruce 2002, Edwards 2003, Hinman i998, Resnick } \\
\text { 2001, Yardley 2002. }\end{array}$ \\
\hline $\begin{array}{l}\text { Evaluation of compliance } \\
\text { (on intervention group of } \\
\text { an RCT/controlled trial) } \\
(\mathrm{n}=2)\end{array}$ & Boyette I997, Cumming 200 I. \\
\hline Process evaluation $(n=2)$ & Allen I999, Gavin 2000 (included a qualitative element). \\
\hline
\end{tabular}

T A в L E 6. Quality assessment of the qualitative studies

Study

仓ั

Aminzadeh 1998

Ballinger 2000

Butler i998

Cameron 1994

Cheal 200I

Clemson 1999

C. of Australia $2000^{1}$

Gavin 2003

Grossman 2003

HEBS $2003^{2}$

Resnick 2000

Sharon 1997

Simpson 2003

Stead 1997

Yardley 2005

$\begin{array}{llllllll}+ & \sim & + & + & + & + & + & 6.5 \\ + & + & \sim & + & + & \sim & + & 6.0 \\ \sim & + & + & + & + & - & ? & 4.5 \\ + & + & + & + & \sim & \sim & \sim & 5.5 \\ + & - & + & + & \sim & \sim & \sim & 4.5 \\ + & \sim & + & + & + & + & ? & 5.5 \\ \sim & + & + & \sim & - & - & \sim & 3.5 \\ \sim & \sim & + & \sim & - & \sim & \sim & 3.5 \\ \sim & - & + & \sim & \sim & \sim & + & 4.0 \\ + & + & + & + & + & + & + & 7.0 \\ + & + & + & + & + & + & + & 7.0 \\ + & - & \sim & + & \sim & + & \sim & 4.5 \\ + & - & + & + & + & + & \sim & 5.5 \\ + & + & \sim & + & \sim & \sim & \sim & 5.0 \\ + & + & + & \sim & - & - & + & 4.5\end{array}$

Notes + yes, - no, $\sim$ partly, ? not clear. I. Health Education Board for Scotland. 2. Department of Health and Age Care, Commonwealth of Australia. 3. Aggregate of scores for each attribute (I for 'yes', 0.5 for 'partly').

which were over 80 per cent. Four reported that they used validated outcome measures (Bruce, Devine and Prince 2002; Edwards et al. 2003; Resnick 200I; Yardley and Smith 2002). 


\section{Reactions to three types of intervention}

\section{General studies of falls and falls prevention}

Four of the eight studies of older people's perspectives on falls and falling in this category used qualitative methods (Ballinger and Payne 2000; Commonwealth of Australia 200o; Health Education Board for Scotland 2003; Simpson, Darwin and Marsh 2003) and one used quantitative methods (Hinman I998). One study (Cheal and Clemson 200I) used quantitative and qualitative methods to examine falls and self-efficacy, and one (Yardley and Todd 2005) used mixed methods to study issues around the communication of the risk of falling and prevention strategies. One study (Allen and Simpson I999) was a process evaluation that explored recruitment to, and attendance at, a falls-prevention programme.

It emerged that the term 'falls prevention' is unfamiliar to many older people (Commonwealth of Australia 2000) and that some are unaware of the benefits of falls-prevention interventions (Simpson, Darwin and Marsh 2003). Although many people accepted that environmental and personal changes might prevent falling, they tended to advocate change for others rather than themselves (Health Education Board for Scotland 2003; Hinman I998). Other issues around falls and falls prevention that were noted included stigma, denial, identity, the attribution of falls to external factors, and low health expectations.

\section{Studies of exercise interventions}

Eleven studies looked at factors that affect participation in, and adherence to, physical activity routines. Some examined exercise in general whereas others focused on specific exercise programmes such as strength training (Boyette, Sharon and Brandon I997; Sharon et al. I997), walking (Resnick and Spellbring 2000), and T'ai Chi and line dancing (Gavin and Myers 2003). One study examined whether fear of falling deterred physical activity (Bruce, Devine and Prince 2002), and a randomised controlled trial assessed the effect of an intervention to promote exercise (Resnick 2002). Many of the studies did not treat exercise as a falls-prevention intervention but as a challenge that promotes general health; those that did showed that many people are unaware of the benefits of exercise in preventing falls (Simpson, Darwin and Marsh 2003; Yardley and Todd 2005).

The factors shown to increase participation in exercise programmes were high exercise self-efficacy, past exercise history, good general health, and unimpaired functional abilities (Rejeski et al. i997; Resnick and Spellbring 2000; Resnick 200I). Among the programme characteristics shown to improve adherence were: frequent bouts of activity of moderate 
duration (Rejeski et al. 1997), accessibility, transport, convenience, having a social dimension, strong leadership (Boyette, Sharon and Brandon I997; Gavin and Myers 2003; Sharon et al. 1997), and exercise tailored to individual needs and capabilities (Gavin and Myers 2003). In addition, an intervention to help people learn about exercise and overcome barriers appeared to increase overall activity and exercise at six months, but the sample size was small and the follow-up was limited (Resnick 2002). The factors shown to be associated with the avoidance of exercise included greater age (Yardley and Smith 2002), fear of falling (Bruce, Devine and Prince 2002), fear of exertion (Grossman and Stewart 2003), and discomfort such as pain or shortness of breath (Simpson, Darwin and Marsh 2003; Resnick and Spellbring 2000).

\section{Studies of home modifications and assistive devices}

Two studies explored factors in adherence to prescribed home modifications (Clemson, Cusick and Fozzard I999; Cumming et al. 200I) and one examined the use of bathroom-safety devices such as grab-bars (Edwards et al. 2003). Three of the general studies (reviewed above) also looked at home modifications (Commonwealth of Australia 2000; Hinman 1998; Simpson, Darwin and Marsh 2003). The other two studies (Aminzadeh and Edwards 1998, 2000) examined the factors that affect the use of assistive devices such as canes. Shared findings were that many see 'homehealth checks' as intrusive and unnecessary, that people dislike changes to their home, and that many have a perception of low risk (Clemson, Cusick and Fozzard 1999; Simpson, Darwin and Marsh 2003). The tendency to reject home-safety advice may be related to older people's wish to maintain their independence and control over their lives and homes (Clemson, Cusick and Fozzard 1999). Barriers to the use of canes and walking aids included stigma, embarrassment, fear of dependence, and denial of the need. Home modifications and walking aids were more acceptable than eyesight and footwear checks, medication reviews, and balance and exercise programmes (Commonwealth of Australia 2000).

\section{Gross-cutting themes}

\section{Barriers and facilitators}

The most common barriers and facilitators relating to participation and adherence to falls-prevention programmes that were identified by two reviewers in the quantitative and qualitative studies are shown in Table 7. Among the barriers to participation and concordance, one that emerged 
T А в L E 7. Facilitators and barriers for older people participating in falls-prevention interventions

Facilitators

Barriers

\section{A. General}

Information that falls can be preventable

Communicating life-enhancing aspects of strategies, e.g. maintaining independence and control

Accessible, appealing information format, from a variety of sources and in different languages

Choice of interventions for different people and lifestyles

High self-efficacy

Personalised modifications

Emphasis on social aspects of interventions

\section{B. Exercise}

Previous exercise 'habit'

Making exercise fun/enjoyable/ sociable

Good leadership/facilitation

Motivation/information about

physical and psychological benefits of exercise

Programmes tailored to needs or lifestyle

Convenient scheduling/ reasonable pricing/good access and transport

Fatalism/attributing falls to external causes/lack of knowledge about effectiveness of falls prevention

Perception that physical deterioration inevitable with age

Lack of relevant information in appropriate formats/ language

Provision of 'one size fits all' advice. Advice seen as common sense/patronising

Low self-efficacy. Fear of loss of independence/risktaking ability

No perception of need for help (no previous falls)

Provoking fear of falling by using scare tactics Social stigma: association with old age/frailty

Differing agenda of older people and health professionals

No previous exercise 'habit'

Physical discomfort/unpleasant sensations associated with exercise

Underlying beliefs about personality type (e.g. too lazy, no willpower)

Self perception: too old to exercise

Poor knowledge of suitable exercises

Commitment and high cost. Poor access/awareness

\section{G. Home modifications/assistive devices}

Facilitate feeling of ownership of interventions, shared decision-

Dislike of interventions seen as intrusive/didactic making

Referral from health-care professional (especially doctor)

Stigma of devices associated with old age

strongly was fatalistic attitudes. Falls were often attributed to chance or bad luck and therefore not regarded as preventable. Several of the studies present similar quotations from their respondents that demonstrate this attitude, for example, 'I don't know how you can be told how to prevent falling. You don't do it on purpose ... it just happens' (Yardley and Todd 
2005: i6). This idea extended to people's rational for not exercising. Some respondents were reported as fatalistically believing that they were basically a lazy person or lacked willpower and therefore could not exercise (Resnick and Spellbring 2000).

A widespread finding was the attribution of falls to external causes, and a complementary resistance to admitting 'intrinsic' risk factors, such as poor eyesight or dizziness (Commonwealth of Australia 2000). Instead, falls were often attributed to external causes, such as the incompetence of others or inevitable physical deterioration, over which the individual had no control (Allen and Simpson I999; Ballinger and Payne 2000). One of many participants' quotations that illustrated this well is found in the Health Education Board for Scotland (2003: I7) study: 'You couldn't have prevented it; it was just the corner of the pavement or something. You know something that anybody of any age could do'. In contrast, Hinman (I998) reported that 68 per cent of the participants related their falls to intrinsic rather than environmental factors, but this study had a small sample and used a brief questionnaire with closed questions that may have been leading.

Some people felt falls-prevention interventions were not appropriate for them because they had low health expectations and saw physical decline as an inevitable consequence of ageing. A characteristic expression was, 'I did a lot of exercise in years gone by ... but in recent years, no[t so]. At my age I guess I don't believe it makes a difference' (Resnick and Spellbring 2000: 39). The opposite views were also reported. Evidently many older people reject the idea that they need falls-prevention advice or help because they see themselves as fit, healthy and able to manage (Allen and Simpson 1999). They may wish to distance themselves from the identity of an 'older' person, and see falls prevention as more relevant for 'older' or 'frailer' people (Yardley and Todd 2005: I3). They may, therefore, be alienated by information that is explicitly targeted at older people or that encourages participation by stereotyping older people (Aminzadeh and Edwards I998; Ballinger and Payne 2000; Health Education Board for Scotland 2003; Stead et al. I997; Yardley and Todd 2005), and dislike advice that they see as common sense and find patronising (Yardley and Todd 2005: I4). Although some fit and active older people may understandably deny the impact of ageing, some of those at high risk and of those with a history of falls also saw falls-prevention advice as relevant to others not themselves (Yardley and Todd 2005).

Related to the issue of identity is the perception of stigma. People often felt stigmatised by interventions aimed at 'older people', for example canes, walking frames and grab-bars (Aminzadeh and Edwards 2000: 30o). Pride also played a part in people being reluctant to accept advice or 
help (Yardley and Todd 2005: 14). Activities that allowed older people to defy stereotypes (e.g. intense exercise programmes) may facilitate participation (Sharon et al. 1997). A contradiction was found, however, between people not wanting to be seen as 'old' and distancing themselves from other 'old' people, and the fact that many valued programmes or interventions that involved contact with people of a similar age and outlook (Stead et al. 1997; Sharon et al. 1997).

\section{Independence and risk negotiation}

The studies confirm that many older people see independence as very important. Some disliked interventions that they saw as didactic or intrusive (Simpson, Darwin and Marsh 2003). They wanted to maintain their independence and make their own decisions and risk assessments (Clemson, Cusick and Fozzard i999). A Scottish participant put this well: 'I think if you've been independent all your life, it's an embarrassment to be dependent' (Health Education Board for Scotland 2003: 27). A fear of falling can lead to a loss of confidence, adversely affect participation in daily activities, and be a barrier to participation in interventions such as exercise (Bruce, Devine and Prince 2002; Cheal and Clemson 2001; Grossman and Stewart 2003; Yardley and Smith 2002). Commonly feared consequences of falling included physical damage, loss of independence, damage to identity, and embarrassment and stigma associated with falling, particularly in a public place (Health Education Board for Scotland 2003; Yardley and Smith 2002). Fear of falling could be made worse by hazard-reduction advice that was frightening and oppressive (Yardley and Todd 2005).

\section{Social interaction and support}

For some participants who disliked group activities, the social aspect of falls-prevention interventions was a barrier (Allen and Simpson i999), but it seems the majority of people preferred interventions with a strong social and recreational component (Allen and Simpson i999; Boyette, Sharon and Brandon 1997; Stead et al. 1997; Sharon et al. 1997). Social support was important at several levels. Family and friends had a role in encouraging participation in, and adherence to, falls-prevention programmes (Cameron and Quine 1994; Grossman and Stewart 2003; Sharon et al. 1997). In addition, the desire to remain healthy and active so as not to be a 'burden' and to keep up with family and grandchildren was an incentive for some to exercise (Grossman and Stewart 2003). Support from programme leaders was also important with strong leadership a facilitator to exercise adherence (Boyette, Sharon and Brandon 1997; Sharon et al. 1997). 


\section{Previous experience}

Previous experience of falls-prevention programmes was an important factor in acceptance of and participation in the interventions, and similarly participation in and adherence to exercise was more likely among those with a history of taking exercise (Resnick and Spellbring 2000; Resnick 200 ; Stead et al. 1997). One study found that a 'habit' of exercise was the strongest predictor of future exercise behaviour (Rejeski et al. 1997). There was mixed evidence about whether having fallen previously might affect attitudes towards falls prevention. Some studies found that those who had fallen before were more likely to be receptive to falls-prevention interventions (Commonwealth of Australia 2000; Edwards et al. 2003), but this was not corroborated by another study (Cumming et al. 200I).

\section{The role of the healthcare professional}

Health-care professionals, particularly physicians, emerged as important social referents for older people (Aminzadeh and Edwards 2000; Commonwealth of Australia 2000; Grossman and Stewart 2003), although one study (Stead et al. 1997) found that they were not perceived as a credible source of information or advice on exercise. Home visits were sometimes seen as an intrusion but this reaction depended on the perceived authority of the person making the visits and recommendations: (Simpson, Darwin and Marsh 2003). Therapists and patients may not share the same agenda and perspectives about falls (Ballinger and Payne 2000); that is, concordance is not present, and professionals need to take into account older people's views and understand and empathise with their risk-taking behaviour (Clemson, Cusick and Fozzard ı999, Simpson, Darwin and Marsh 2003).

\section{Discussion}

The systematic review found 24 studies that examined some aspect of older people's attitudes towards falls prevention. Twelve used qualitative methods and the rest quantitative designs. The majority were exploratory studies and collected older people's views on falls and falls prevention. The studies identified a number of factors that affected participation in falls-prevention interventions and programmes. These included denial, fatalism, self-efficacy, past exercise habits, a fear of falling, general health and functional ability, health expectations, under-estimation of personal risk of falling, stigma, embarrassment, and the inconvenience of some assistive devices. 
Of particular interest were those aspects of falls-prevention programmes that improved participation and adherence, and the studies provided evidence that social support and interaction, low intensity exercise (e.g. walking), education, and the perception that a programme was relevant and beneficial had these effects. Social support was very important in reinforcing engagement with falls-prevention interventions, both at the individual level (i.e. from health-care professionals, family, friends) and at the societal level (i.e. wider cultural norms that support the idea of older people remaining active).

Many of the themes identified by the review, e.g. identity, stigma, independence, denial of the ageing process and health expectations, concern the ways in which older people view themselves and believe they are seen by others. The social identity of older people is sometimes stigmatised, incorporating references to disability, disenfranchisement and other negative attributes. The way dependency is emphasised as a concomitant of old age is culturally constructed and historically located (Chater I999; McCormack 2003). Discrimination towards older people has been described throughout the British National Health Service and social-care services (Grimley Evans 1997; Department of Health 200I), and is pervasive in society, which adds to older people's disempowerment (Bytheway I995; Tones 1998). Those working with older people to prevent falls therefore need to be aware of, and to challenge, the factors that sustain their marginalised position (Ryles I999).

One of the aims of the review was to assess the effectiveness of interventions used to promote the acceptance of falls-prevention strategies and to identify examples of good practice, but only one very small study that evaluated the promotion of adherence to a falls-prevention intervention was found (Resnick 2002). The majority of the reviewed studies were exploratory. The facilitators of participation were identified more often by inference or by the investigators' 'subjective synthesis' than by a statistically significant effect from a controlled study. Many of the studies examined only beliefs and attitudes, not actual behaviour. The presented evidence allows us to speculate about the key factors in successful interventions but these need further evaluation.

Several paradoxes that are challenges for those designing fallsprevention programmes emerged from the review. On the one hand, some people reject interventions that stereotype them as 'old' and wishing to avoid contact with other older people, but on the other hand, many people valued interventions that involved contact with people of a similar age and outlook. Another evident challenge is how health practitioners make people aware of their potential risk of falling without causing distress or denial of the problem. 


\section{Limitations and strengths of the review}

A number of the review's methodological features could influence the validity of its results. Publication and other selection biases threaten the validity of all systematic reviews, but this is a particular problem when searching for studies that used non-randomised designs. These are more difficult to identify than randomised-controlled trials, because of the diversity of designs, the absence of standardised terminology, and the limitations of key-wording or cataloguing (Peersman et al. I998). Despite our efforts to identify all eligible published and unpublished studies, we cannot exclude the possibility that some were missed. The included studies use several different methodologies. Although methods for conducting syntheses and meta-analyses of trials are well established (Egger, Davey-Smith and Altman 200I; Green and Higgins 2005), several approaches have been proposed for reviewing qualitative and non-randomised studies and they are still being developed (Campbell 2003; Dixon-Woods, Fitzpatrick and Roberts 200i; Harden et al. 2004).

There are also issues around quality assessment, both in terms of which quality criteria should be used and how that information should be applied to the review findings (Dixon-Woods Fitzpatrick and Roberts 200I; Sandelowski, Docherty and Emden 1997). In addition, there is no consensus on whether studies should be weighted by design and quality. Therefore, although we critically appraised the qualitative studies in the review, we did not use this information to exclude studies or weight the results. More work is needed on the tools and procedures for quality assessments of qualitative studies in systematic reviews. Despite these issues, a narrative synthesis provides a valuable overview of evidence from disparate studies, and usefully identifies the contributions of such studies to the evidence base. In particular, it collates the evidence about patient perspectives on falls prevention, which have been neglected in the development and implementation of the interventions.

The generalisability of the review findings must be considered. The studies in this review sampled older people from both community and extended-care settings. Although a few attempted to assess the efficacy of an intervention or reported associations with very few respondents, the majority had acceptable sample sizes. In addition, although some of the studies acknowledged the problems of generalisation, there was impressive consistency in the prominent themes. On the other hand, few participants were from non-English speaking backgrounds, there were few data on gender or social-class differences, and those with cognitive impairments were usually excluded. 


\section{Conclusions}

Much research has been done on which interventions are effective in preventing falls and there have been systematic reviews (Cryer 200I; Easterbrook et al. 200 ; Gillespie et al. 2003; Parker, Gillespie and Gillespie 2005), but the little evidence of the factors that influence participation and long-term adherence has not previously been collated. Gender and ethnicity may affect attitudes towards and participation in falls-prevention strategies but there is no research on these factors (Horton 2002). Currently, the health-care and other professionals that are developing or providing falls-prevention services have little knowledge of either older people's views or the barriers to their participation that older people perceive. Further research that raises understanding of the factors that influence older people's ambivalence towards falls-prevention interventions and that promote their continuing involvement will improve service design and effectiveness.

\section{Acknowledgements}

This work was as part of a larger project, 'Facilitators and barriers to older people accepting and complying with interventions to reduce falling and fractures', that was funded by the Department of Health for England through the Accidental Injury Prevention Programme. The views expressed in the publication are those of the authors and not necessarily those of the Department of Health.

\section{References}

Allen, A. and Simpson, J. M. I999. A primary care based falls prevention programme. Physiotherapy Theory and Practice, 15, 2, 12 I-33.

Aminzadeh, F. and Edwards, N. 1998. Exploring seniors' views on the use of assistive devices in falls prevention. Public Health Nursing, I5 4, 297-304.

Aminzadeh, F. and Edwards, N. 200o. Factors associated with cane use among community dwelling older adults. Public Health Nursing, I 7, 6, 474-83.

Ballinger, C. and Payne, S. 2000. Falling from grace or into expert hands? Alternative accounts about falling in older people. British fournal of Occupational Therapy, 63, I2, 573-9.

Boyette, L. W., Sharon, B. F. and Brandon, L. J. 1997. Exercise adherence for a strength training program in older adults. Fournal of Nutrition, Health and Aging, I, 2, 93-7.

Bruce, D. G., Devine, A. and Prince, R. L. 2002. Recreational physical activity levels in healthy older women: the importance of fear of falling. Fournal of the American Geriatric Society, 50, I, 84-9.

Butler, M., Coggan, C. and Norton, R. I998. A qualitative investigation into the receptivity to hip protective underwear among staff and residents of residential institutions. New Zealand Fournal of Medicine, I I I, I075, 383-5.

Bytheway, B. I995. Ageism. Open University Press, Buckingham. 
Cameron, I. D. and Quine, S. I994. External hip protectors: likely non-compliance among high risk elderly people living in the community. Archives of Gerontology and Geriatrics, r 9, 3, 273-8I.

Campbell, R., Pound, P., Pope, C., Britten, N., Pill, R. and Morgan, M. 2003. Evaluating meta-ethnography: a synthesis of qualitative research on lay experiences of diabetes and diabetes care. Social Science and Medicine, 56, 40, 67I-84.

Chandler, J. M., Duncan, P. W., Sanders, L. and Sudenski, S. I996. The fear of falling syndrome: relationship to falls, physical performance and activities of daily living in frail older persons. Topics in Geriatric Rehabilitation, I I , I, 55-63.

Chater, K. I999. Risk and representation: older people and non-compliance. Nursing Inquiry, 6, 2, I32-8.

Cheal, B. and Clemson, L. 200I. Older people enhancing self-efficacy in fall-risk situations. Australian Occupational Therapy Journal, 48, 2, 80-9I.

Clemson, L., Cusick, A. and Fozzard, C. I999. Managing risk and exerting control: determining follow through with falls prevention. Disability and Rehabilitation, 2 I, I2, 53 I-4I.

Commonwealth of Australia 2000. National Falls Prevention for Older People Initiative 'Step Out with Confidence': A Study into the Information Needs and Perceptions of Older Australians Concerning Falls and Their Prevention. Department of Health and Aged Care, Commonwealth of Australia, Canberra.

Cryer, C. 200I. What Works to Prevent Accidental Injury Among Older People? Health Development Agency, London.

Cumming, R. G., Thomas, M., Szonyi, G., Frampton, G., Salkeld, G. and Clemson, L. 200I. Adherence to occupational therapist recommendations for home modifications for falls prevention. American Fournal of Occupational Therapy, 55, 6, 641-8.

Cummings, S. R., Kelsey, J., Nevitt, M. and O’Dowd, K. I985. Epidemiology of osteoporosis and osteoporotic fractures. Epidemiological Reviewes, 7, I78-208.

Department of Health 200I. National Service Framework for Older People. Department of Health, London.

Dixon-Woods, M., Fitzpatrick, R. and Roberts, K. 200I. Including qualitative research in systematic reviews: opportunities and problems. Fournal of Evaluation in Clinical Practice, 7, 2, $125-33$.

Easterbrook, L., Horton, K., Arber, S. and Davidson, K. 200I. International Review of Falls in Older People. Report for the Health Development Agency and Department of Trade and Industry (DTI), DTI, London.

Edwards, N., Lockett, D., Aminzadeh, F. and Nair, R. 2003. Predictors of bath grab-bar use among community-living older adults. Canadian fournal on Aging, 22, 2, $217-27$.

Egger, G., Davey-Smith, G. and Altman, D. (eds) 2001. Systematic Reviewes in Health Care: Meta-analysis in Context. BMJ Books, London.

Gavin, T. S. and Myers, A. M. 2003. Characteristics, enrolment, attendance, and dropout patterns of older adults in beginner Tai-chi and line-dancing programs. Fournal of Aging and Physical Activity, I I, I, I23-4I.

Giacomini, M. and Cook, D. 200o. User's guide to the medical literature: XXIII. Qualitative research in health care. B. What are the results and how do they help me care for my patients? Evidence Based Medicine Working Group. Fournal of American Medical Association, 284, 4, 478-82.

Gillespie, L. D., Gillespie, W.J., Robertson, M. C., Lamb, S. E., Cumming, R. G. and Rowe, B. H. Interventions for preventing falls in elderly people. Cochrane Database of Systematic Reviewes 2003, Issue 4. Art. No.: CDooo340. DOI: I0.1002/14651858. CDooo340.

Green, S. and Higgins, J. (eds) 2005. Cochrane Handbook for Systematic Reviewes of Interventions. Version 4.2.5 (updated May 2005), Available online at http://www.cochrane.org/ resources/handbook/hbook.htm [Accessed June 2005]. 
Grimley Evans, J. 1997. The rationing debate. Rationing healthcare by age: the case against. British Medical Fournal, 314, 822.

Grossman, M. D. and Stewart, A. L. 2003. 'You aren't going to get better by just sitting around': physical activity perceptions, motivations, and barriers in adults 75 years of age or older. American foumal of Geriatric Cardiology, I 2, I, 33-7.

Harden, A., Garcia, J., Oliver, S., Rees, R., Shepherd, J., Brunton, G. and Oakley, A. 2004. Applying systematic review methods to studies of people's views: an example from public health research. Fournal of Epidemiology and Community Health, 58, 9, 794-80o.

Health Education Board for Scotland 2003. The Construction of the Risks of Falling in Older People: Lay and Professional Perspectives. Health Education Board for Scotland, Edinburgh.

Higgins, J. P. T. and Green, S. (eds) 2006. Cochrane Handbook for Systematic Reviews of Interventions 4.2.6. Online Cochrane Library. Available online at http://www.cochrane. org/resources/handbook/hbook.htm [Accessed 6 October 2006].

Hinman, M. R. 1998. Causal attributions of falls in older adults. Physical and Occupational Therapy in Geriatrics, $\mathbf{1} 5,3,7 \mathrm{I}-84$.

Horton, K. 2002. Gender and Falls: Older People and Key Family Members' Perspectives. Unpublished PhD thesis, Department of Sociology, University of Surrey, Guildford, Surrey.

Jensen, G. F., Christiansen, G., Boesen, J., Hegedus, V. and Transbol, I. I982. Epidemiology of postmenopausal spinal and long bone fractures: a unifying approach to postmenopausal osteoporosis. Clinical Orthopaedics, I66, 75-8I.

Lachman, M. E., Howland, J., Tennstedt, S., Jette, A., Assmann, S. and Peterson, E. W. 1998. Fear of falling and activity restriction: the survey of activities of fear of falling in the elderly (SAFE). Fournal of Gerontology: Psychological Sciences, 53B, I, 43-50.

Lilley, J., Arie, T. and Chilvers, C. I995. Accidents involving older people: a review of the literature. Age and Ageing, 24, 4, 346-65.

Lu-Yao, G. L., Baron, J. A., Barrett, J. A. and Fisher, E. S. 1994. Treatment and survival among elderly Americans with hip fractures: a population-based study. American fournal of Public Health, 84, 8, I287-9I.

Magaziner, J., Simonsick, E. M., Kashner, T. M., Hebel, J. R. and Kenzora, J. E. I989. Survival experience of aged hip-fracture patients. American fournal of Public Health, 79, 3, $274^{-8 .}$

Mays, N. and Pope, C. 1995. Qualitative research: rigour and qualitative research. British Medical Fournal, 3I I , I09-12.

McCormack, B. 2003. A conceptual framework for person-centred practice with older people. International Fournal of Nursing Practice, 9, 3, 202-9.

National Institute for Health and Clinical Excellence (NICE) 2004. Falls: The Assessment and Prevention of Falls in Older People: Clinical Guideline. NICE, London.

Parker, M. J., Twemlow, T. R. and Pryor, G. A. I996. Environmental hazards and hip fractures. Age and Ageing, 25, 4, 322-5.

Parker, M. J., Gillespie, W.J. and Gillespie, L. D. 2005. Hip Protectors for Preventing Hip Fractures in Older People. Cochrane Database of Systematic Reviews 2005, Issue 3. Available online at http://www.cochrane.org/reviews/en/aboor255.html [Accessed 26 September 2007].

Peersman, G., Harden, A., Oliver, S. and Oakley, A. I. I998. Reviewes of Effectiveness in Health Promotion. Report for the Department of Health, EPPI-Centre, London.

Rejeski, W.J., Brawley, L. R., Ettinger, W., Morgan, T. and Thompson, C. 1997. Compliance to exercise therapy in older participants with knee osteoarthritis: implications for treating disability. Medicine and Science in Sports and Exercise, 29, 8, 977-85.

Resnick, B. 200I. A prediction model of aerobic exercise in older adults living in a continuing-care retirement community. Fournal of Aging and Health, $\mathbf{1} 3$, 2, 287-310. 


\section{Frances Bunn et al.}

Resnick, B. 2002. Testing the effect of the WALC intervention on exercise adherence in older adults. Fournal of Gerontological Nursing, 28, I, 40-9.

Resnick, B. and Spellbring, A. M. 2000. Understanding what motivates older adults to exercise. Fournal of Gerontological Nursing, 26, 3, 34-42.

Ryles, S. M. 1999. A concept analysis for empowerment: its relationship to mental health nursing. Fournal of Advanced Nursing, 29, 3, 600-7.

Sandelowski, M., Docherty, S. and Emden, C. 1997. Qualitative metasynthesis: issues and techniques. Research in Nursing and Health, 2o, 4, 365-7I.

Sharon, B. H., Hennessy, C. H., Brandon, J. and Boyette, L. I997. Older adults' experiences of a strength training program. Fournal of Nutrition, Health and Aging, I, 2, I03-8.

Simpson, J. M., Darwin, C. and Marsh, N. 2003. What are older people prepared to do to avoid falling? A qualitative study in London. British fournal of Community Nursing, 8, 4, I52, I54-9.

Spencer, L., Ritchie, J., Lewis, J. and Dillon, L. 2003. Quality in Qualitative Evaluation: A Framework for Assessing Research Evidence. Government Chief Social Researcher's Office, Cabinet Office, London. Available online at http://www.policyhub.gov.uk/docs/ a_quality_framework.pdf [Accessed 26 September 2007].

Stead, M., Wimbush, E., Eadie, D. and Teer, P. I997. A qualitative study of older people's perceptions of ageing and exercise: the implications for health promotion. Health Education Fournal, 56, I, 3-16.

Thomas, J., Sutcliffe, K., Harden, A., Oakley, A., Oliver, S., Rees, R., Brunton, V. and Kavanagh, J. 2003. Children and Healthy Eating: A Systematic Review of Barriers and Facilitators. Social Science Research Unit, EPPI Centre, Institute of Education, University of London, London.

Tones, K. 1998. Empowerment for health: the challenge. In Kendall, S. (ed.), Health and Empowerment. Arnold, London, I85-204.

Yardley, L. and Smith, H. 2002. A prospective study of the relationship between feared consequences of falling and avoidance of activity in community-living older people. The Gerontologist, 42, I, I7-23.

Yardley, L. and Todd, C. 2005. Encouraging Positive Attitudes to Falls Prevention in Later Life. Help the Aged, London.

Address for correspondence:

Accepted 28 September 2007

Frances Bunn, Senior Research Fellow, Centre for Research in Primary and Community Care, University of Hertfordshire, College Lane Campus, Hatfield ALio 9AB, UK.

E-mail: f.bunn@herts.ac.uk 